\title{
A study of ablation variations on the tongue of Hintereisferner, Austrian Alps
}

\author{
R. S. W. van de Wal, J. Oerlemans and J. C. VAn DeR Hage \\ Instituut voor Marien en Atmosferisch Onderzoek, University of Utrecht, Utrecht, The Netherlands
}

\begin{abstract}
In the summer of 1989 a glacio-meteorological experiment was carried out on Hintereisferner, Austria. Here, we discuss the interpretation of detailed ablation measurements on the tongue. Two profiles are considered: one along the glacier axis and one across the glacier tongue. At the crossing, an energybalance station was operated, providing the necessary meteorological data. At all stakes the albedo was measured several times with a simple light-weight instrument (described separately in the Appendix). The absorption of solar radiation was calculated for all stake positions, taking into account local albedo, slope, aspect and shading effects. It appears that the differences in ablation can be explained almost entirely by the differences in surface albedo, both along and across the glacier tongue.
\end{abstract}

\section{INTRODUCTION}

In July 1989, a glacio-meteorological experiment was carried out on Hintereisferner in the Austrian Alps $\left(46^{\circ} 50^{\prime} \mathrm{N}, 10^{\circ} 50^{\prime} \mathrm{E}\right)$, in a joint project of the University of Innsbruck (Institut für Meteorologie und Geophysik) and the University of Utrecht (Instituut voor Marien en Atmosferisch Onderzoek). In total, ten meteorological field stations were operated for a number of days along the valley axis, extending from the firn area to about $1 \mathrm{~km}$ down from the glacier front. In addition, a cable balloon was used to obtain wind, humidity and temperature profiles up to $700 \mathrm{~m}$ from the elevation of the tongue (effectively up to the height of the surrounding mountain crests). The main purpose of the experiment was to investigate the small-scale circulation induced by the thermal contrast between the glacier and its surroundings, and its effect on the energy budget of the glacier surface. However, several additional topics were also studied. Here, we report on an investigation of spatial variability of ablation rates on the glacier tongue.

The dependence of ablation rates on surface elevation is a well-known feature occurring on almost every mountain glacier. The most important factors are increasing air temperature when going downwards (implying a larger turbulent heat flux and stronger atmospheric counter radiation) and decreasing albedo (e.g. Kuhn, 1979; Oerlemans and Hoogendoorn, 1989). Variation of the melting rate across a glacier, with the largest rates at the sides, have also been noted by a number of workers, but only a few attempts have been made to quantify the contributing factors. Wendler (1975) suggested that the advection of warm air from the warm valley slopes towards the glacier tongue may explain part of the higher melting rates. It seems likely, however, that on many glaciers albedo effects are also very important.

In this study we focus on the question to what extent ablation variations can be related to differences in albedo. For this purpose, ablation as well as albedo were measured along a cross-profile and a longitudinal profile. Measuring the albedo exactly at the position of the stake was considered essential, and a small "mini-albedometer" was used for this (it is described in the Appendix). Apart from the direct correlation between albedo and ablation, we also discuss the significance of geometric factors (slope and aspect as well as shading effects) by using these in a calculation of absorbed solar radiation for all stakes.

\section{THE MEASUREMENTS}

Part of the experimental set-up is shown in Figure 1. Locations of the stakes in the cross- and longitudinal profile are numbered $(\mathrm{Cl} \ldots \mathrm{C} 8)$ and $(\mathrm{Ll} \ldots \mathrm{L} 9)$, respectively. Three stakes of the existing University of Innsbruck network were used. At C3 (=L3), meteorological parameters were measured at a $10 \mathrm{~m}$ mast: temperature at $0.5,2$ and $10 \mathrm{~m}$; humidity at $2 \mathrm{~m}$; wind direction at $10 \mathrm{~m}$; wind speed at $0.5,1,2$ and $10 \mathrm{~m}$. The temperature and humidity sensors were ventilated to prevent radiation errors. Short- and long-wave radiation were measured $1.5 \mathrm{~m}$ above the glacier surface with Aanderaa pyrano- and pyrradiometers, types 2770 and 2811 , respectively. All sensors were sampled every $2 \mathrm{~min}$, and at regular intervals the data were transmitted by radio to a central receiving station in the village of Vent. The instruments were checked almost every day and 


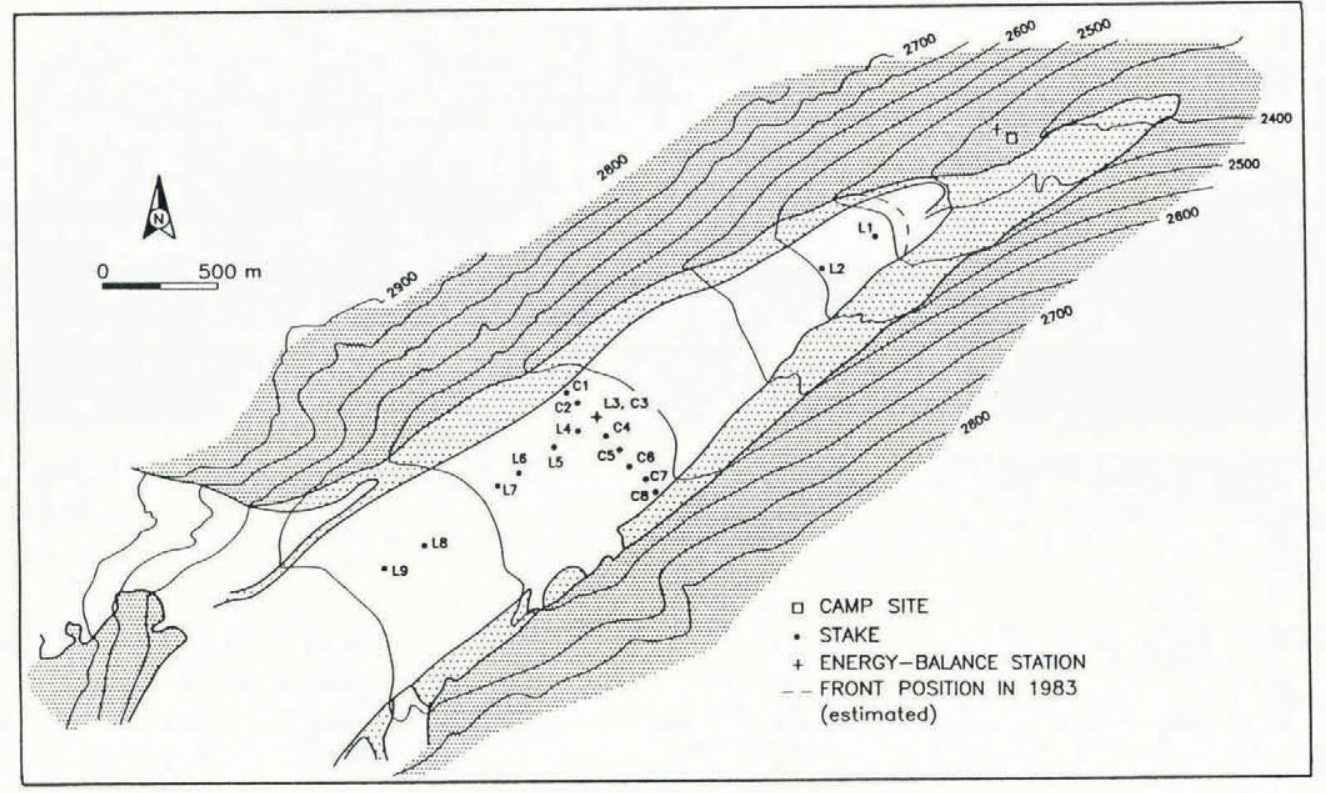

Fig. 1. Map of the tongue of Hintereisferner (based on Kuhn, 1981). The estimated 1989 front position is shown by the dashed line. Two profiles were studied, one along and one across the glacier tongue.

hand measurements were done in the nearby camp (see Fig. 1) for comparison. From here the balloon was also operated.

The radiative fluxes at $\mathrm{C} 3$ were measured through a horizontal plane and not parallel to the surface. However, for this site, with a slope of $5^{\circ}$ and an aspect of $045^{\circ}$, the difference should be less than 2\% (Mannstein, 1985). Here, a comparison was also made between the Aanderaa pyranometer and the albedometer (see Appendix for further details). The weakest point of the albedometer is the deviation from true cosine response for small solar elevations. To avoid errors, all measurements with the albedometer were done between 10 and $15 \mathrm{~h}$ local time. In the Appendix, results are presented from a comparison between the Aanderaa sensors and the mini-albedometer as well as a comparison between the mini-albedometer and a conventional thermopile albedometer type SRI 5. Based on these results, we estimate the absolute error in our albedo measurements to be $2 \%$.

Stakes were read and the albedo was measured on 10 , 13, 16, 19, 24 and 28 July, and on 16 September 1989. Reading the stakes was done by placing a $2 \mathrm{~m}$ long rod horizontally (i.e. perpendicular to the slope) against the stake. Although this is not necessarily the best way to deal with local surface irregularities, it at least defines a uniform method. Albedo was measured parallel to the surface, but in fact we found very little change $(<2 \%)$ by orientating the instrument horizontally. As mentioned above, this is because measurements were only carried out at times with a high sun.

\section{ENERGY BUDGET AT C3}

The meteorological measurements at C3 were done from 13 to 30 July. The components of the surface-energy balance obtained for the location C3 are listed in Table 1 . Here, a comparison is made with the 1986 field experiment, where energy-balance measurements were performed on a slightly lower side on the glacier tongue (Greuell and Oerlemans, 1989). In the summer of 1986, the measurements took place during a period of relatively cool but sunny and stable weather. During the 1989 experiment, the weather was much more variable, with showers on many days. In Figure 2, daily totals of global radiation are shown to illustrate this point. Between 10 and 30 July there were no snowfall events on the glacier tongue - virtually all precipitation fell as rain.

Table 1. Comparison of surface-energy balance and ablation for the 1986 and 1989 field experiments

July 1986

July 1989

$\begin{array}{lrr}\text { Elevation of site }(\mathrm{m}) & 2500 & 2630 \\ \text { Mean air temperature }\left({ }^{\circ} \mathrm{C}\right) & 4.0 & 4.6 \\ \text { Mean vapour pressure }(\mathrm{Pa}) & 590 & 420 \\ \text { Mean wind speed }\left(\mathrm{m} \mathrm{s}^{-1}\right) & 2.8 & 3.0 \\ Z_{0}(\mathrm{~mm}) & 1.3 & 5.0 \\ \text { Global radiation }\left(\mathrm{MJ} \mathrm{d}^{-1} \mathrm{~m}^{-2}\right) & 24.3 & 19.7 \\ \text { Albedo } & 0.16 & 0.32 \\ \text { Absorbed solar radiation }\left(\mathrm{MJ} \mathrm{d}^{-1} \mathrm{~m}^{-2}\right) & 20.4 & 13.4 \\ \text { Net long-wave radiation }\left(\mathrm{MJ} \mathrm{d}^{-1} \mathrm{~m}^{-2}\right) & -3.9 & -0.7 \\ \text { Sensible-heat flux }\left(\mathrm{MJ} \mathrm{d}^{-1} \mathrm{~m}^{-2}\right) & 1.9 & 2.8 \\ \text { Latent-heat flux }\left(\mathrm{MJ} \mathrm{d}^{-1} \mathrm{~m}^{-2}\right) & -0.3 & -1.8 \\ \text { Total-energy flux }\left(\mathrm{MJ} \mathrm{d}^{-1} \mathrm{~m}^{-2}\right) & 18.1 & 13.7 \\ \text { Calculated ablation }\left(\mathrm{cm} \mathrm{ice}^{-2}\right. & 61 & 85 \\ \text { Measured ablation }\left(\mathrm{cm} \mathrm{ice}^{2}\right. & 57 & 88 \\ \text { Measured ablation rate }\left(\mathrm{cm} \mathrm{ice} \mathrm{d}^{-1}\right) & 5.7 & 4.7\end{array}$




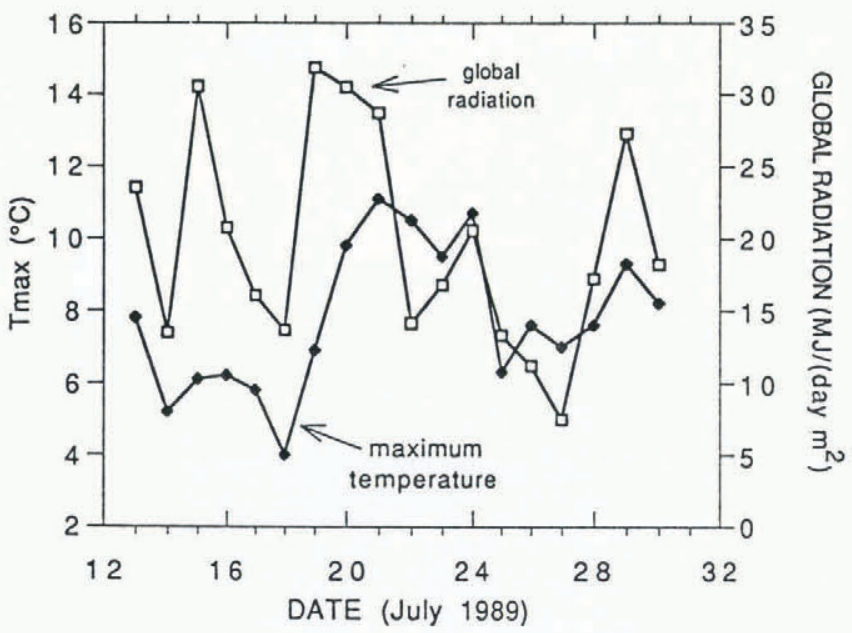

Fig. 2. Daily totals of global radiation and daily maximum temperature as measured at the location C3.

The turbulent fluxes appearing in Table 1 were calculated from the wind profile, the humidity at $2 \mathrm{~m}$ and the temperature at $0.5 \mathrm{~m}$. Unfortunately, logging problems made it impossible to retrieve the temperature measurements at $0.5 \mathrm{~m}$. The mean aerodynamic roughness was found to be $5 \mathrm{~mm}$, which is about 4 times as large as for the 1986 experiment. Roughness length for enthalpy and moisture were taken from the 1986 experiment, but scaled with the factor 4 mentioned above. In any case, the difference in energy budgets between the two experiments is almost entirely due to global radiation - the turbulent fluxes play a minor role. This is due to the generally low albedo.

The ablation calculated from the energy budget is in very good agreement with the measured ablation. The calculation was done by integrating over all times that the surface-energy budget was positive. It should be noted, however, that using the mean energy budget (i.e. straightforward averaging of all data) does give virtually the same result (difference only $3 \mathrm{~cm}$ ice).

\section{ABLATION AND ALBEDO}

The measurements are summarized in Figure 3 for the longitudinal profile and in Figure 4 for the cross-profile. The upper panels give the albedo at three selected days (10, 28 July, 16 September). The lowest values are generally found on 16 September, towards the end of the ablation season. On 10 July, the uppermost point in the longitudinal profile was still covered by old snow. Albedo at the tongue ( $\mathrm{Ll}$ ) was low during the entire ablation season $(0.10-0.16)$. This was due to the accumulated dust and, in particular, the abundant presence of meltwater. In the cross-profile, the highest values were found in the middle $(0.3-0.4)$. Towards the sides of the glacier, the albedo dropped to about 0.2 , on average. The picture emerging here is in good agreement with the study of Dirmhirn and Trojer (1955), who studied the change in surface albedo during a $10 \mathrm{~d}$ period in August, after a summer snowfall event. Their longitudinal albedo profile, after the snow had melted, is very similar to the one found here. Nevertheless, variation of the albedo in time and
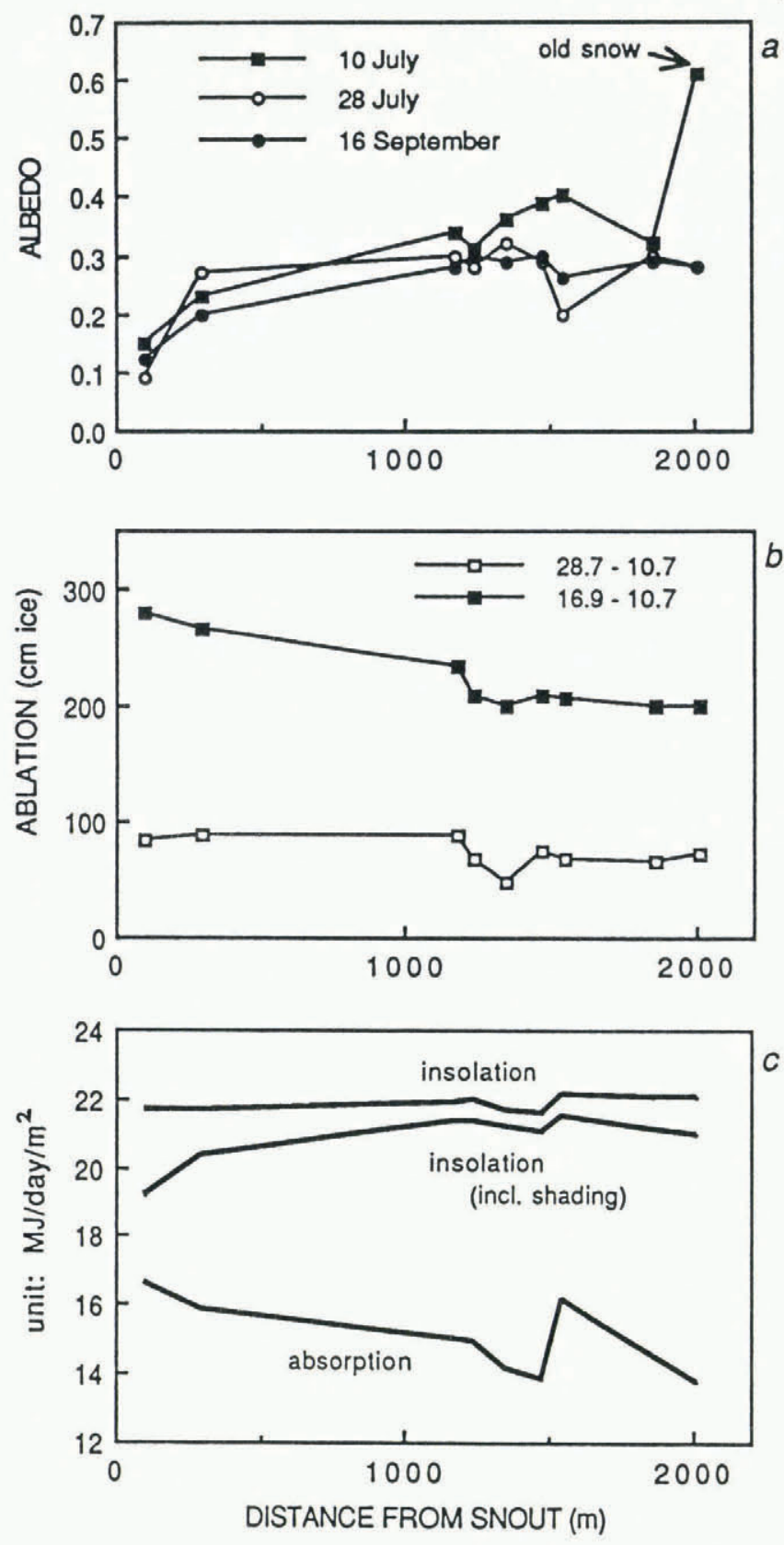

Fig. 3. A summary of the measurements in the longitudinal profile. The albedo is shown on three selected days only (a). Ablation (b) is in $\mathrm{cm}$ ice, obtained directly by subtracting stake readings without making any kind of correction. The results of the calculation on absorbed solar radiation is shown in the lowest panel (c). The curve labelled "insolation" refers to the case where geometric factors (slope and aspect) are taken into account, but not the shading by the mountain crests.

space can be complex. Figure 5 shows the formation of a white crusty layer with a high albedo in the middle of the glacier from 14 to 18 July. During this period, the ablation rate dropped significantly. The measurements presented in this paper do not allow us to make an estimate of the real significance of this type of event, as this would require a detailed treatment of the penetration of solar radiation in the upper ice layers.

In Figures 3 and 4, ablation is shown for two periods: 10-28 July (periỏd 1), and 10 July-16 September (period 2 ). For period 1, the ablation is remarkably constant 

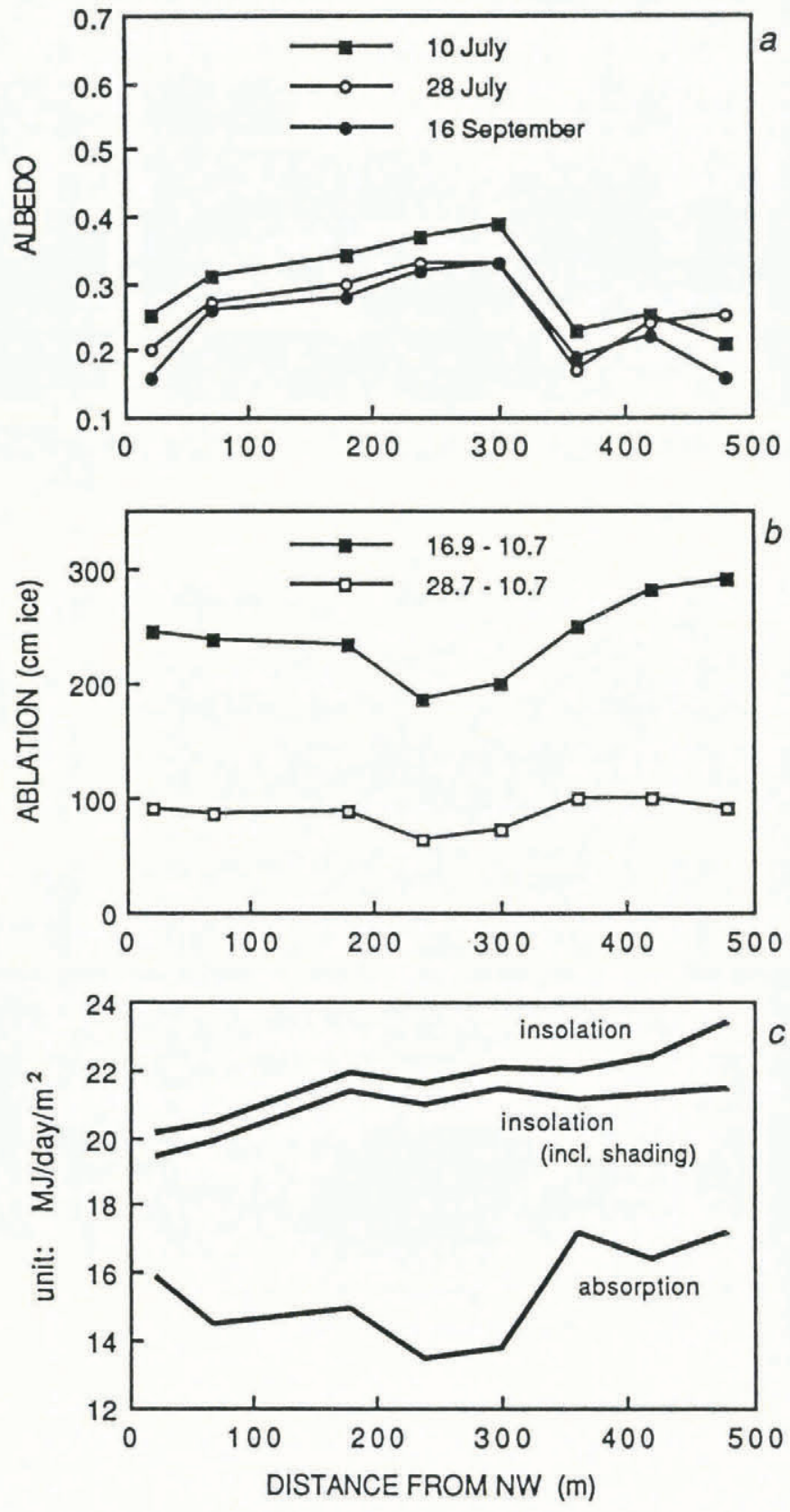

Fig. 4. As Figure 3, but for the cross-profile.

along the glacier tongue. When considering the entire period, a definite trend to lower ablation up-glacier is apparent. In the cross-profile, the southwestern side has the largest ablation rates. The differences between the middle part of the glacier and the sides are quite significant, and larger than those reported by Wendler (1975) for McCall Glacier. The ablation averaged over C1, C2, C7 and C8 is $264 \mathrm{~cm}$ ice. For the centre points, $\mathrm{C} 3, \mathrm{C} 4, \mathrm{C} 5$ and $\mathrm{C} 6$, the mean value is $217 \mathrm{~cm}$.

The absorption of solar radiation was calculated for all stake positions by taking into account slope, aspect and shading effects. Slope and aspect were estimated in the field, and later compared with a detailed map of Hintereisferner (scale 1:10000 (1979) issued by M. Kuhn, University of Innsbruck). This map was also used to estimate the shading horizon for 18 directions for each stake. The calculation was done by using the solarradiation routine in the energy-balance model described by Oerlemans and Hoogendoorn (1989) for a standard

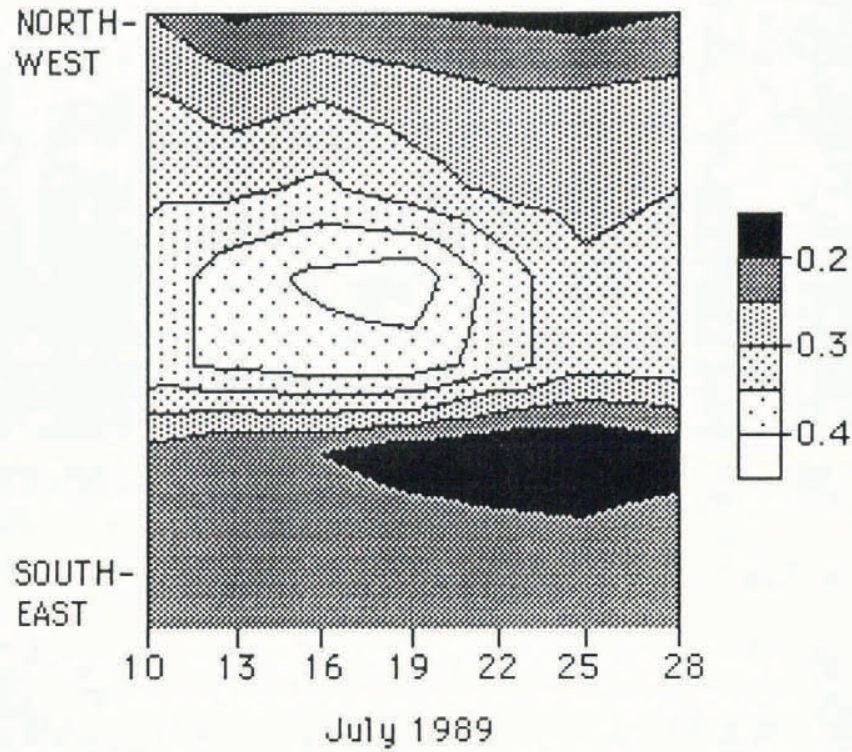

Fig. 5. Illustrating the formation of a crusty layer by a running-time diagram of the measured albedo along the cross-profile.

cloudiness of 0.6. A comparison with the measured global radiation at $\mathrm{C} 3$ (see Table 1) showed a good agreement. The difference could easily be explained by greater cloud cover during the field experiment, and the different period involved. As here the major interest is in variations associated with geometric factors and albedo variations, no attempt was made to make a fine tuning between calculated insolation and the measurements at C3.

The results are given in Figures $3 \mathrm{c}$ and 4c. Insolation and absorption are for unit surface area. The influence of shading is shown separately. It appears to be largest at the snout (reducing the insolation by up to $15 \%$ ). When going up-glacier, the effect of increasing albedo turns out to be partly compensated by increasing insolation (smaller surface slope towards the southwest and less shading). Still, the main reason for strongly varying absorbed radiation is found in the large differences in albedo. In particular, for the cross-profile, the ablation (Fig. 4b) and absorption curves (Fig. 4c) are remarkably similar.

Next, we consider the entire sample of ablation measurements. In Figure 6a, the ablation for period 2 is plotted against the absorptivity, defined as (1-albedo). The relation appears to be significant. A linear-regression model can explain about $70 \%$ of the variance. Taking into account the geometric factors does not improve this result, as is obvious from the plot of ablation against absorption (Fig. 6b). The conclusion must be that the variability of ablation over the glacier tongue can be explained to a large extent by albedo effects.

The slope of the regression in Figure $6 \mathrm{~b}$ is $0.326 \mathrm{~cm}$ ice $\mathrm{MJ} \mathrm{m}^{-2}$. Taking an ice density of $900 \mathrm{~kg} \mathrm{~m}^{-3}$, this converts to $0.36 \mathrm{MJ} \mathrm{kg}^{-1}$, which is very close to the latent heat of fusion for ice $\left(0.334 \mathrm{MJ} \mathrm{kg}^{-1}\right)$. So, indeed, the variability in ablation we measured on the tongue appears to be directly related to the differences in absorbed solar radiation.

During a few days (25-30 July), the configuration of the meteorological equipment was changed to study the 

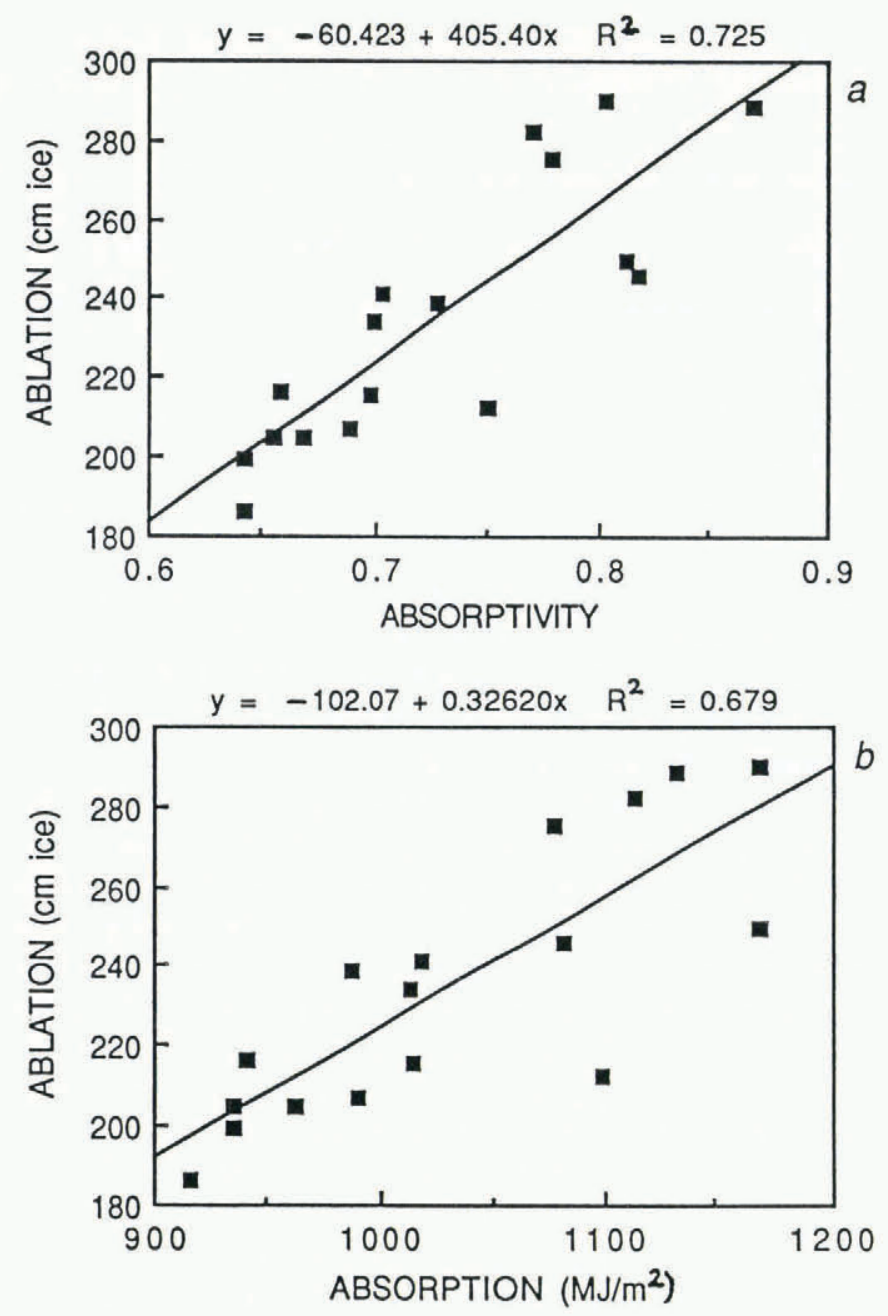

Fig. 6. Scatter diagram of all stake readings versus absorptivity (a) and absorption (b). Apparently, albedo variations explain many of the differences in ablation.

cross-valley circulation. Along the cross-profile on the glacier, meteorological measurements were done at $\mathrm{Cl}$, C3 and C8. Comparing the data revealed that there is only a small difference between air temperature in the middle of the glacier and at the sides. At C3, the mean air temperature over this period was $4.8^{\circ} \mathrm{C}$. At $\mathrm{Cl}$ and $\mathrm{C} 8$ it was $4.1^{\circ}$ and $3.1^{\circ} \mathrm{C}$, respectively. Even after correction for the difference in elevation $\left(<0.2^{\circ} \mathrm{C}\right)$, it appeared that mean air temperature at the sides is slightly lower than in the middle of the glacier; there is a tendency for relatively cold air to accumulate along the glacier margin. Estimating the resulting difference in turbulent-heat flux and extrapolating to the entire period of ablation measurements yields differences in ablation of at most $6 \mathrm{~cm}$ between the middle and the sides of the glacier tongue. This is much less than the differences induced by albedo variations. So the ablation in the middle of the glacier is lower in spite of the slightly higher temperature compared to the side of the glacier. In the light of this, it should be remembered that $90 \%$ of the energy available for melting originates from the radiation balance and less than $10 \%$ from the turbulent-heat flux (see Table 1).

From this result, it should not be concluded that the intense heating of the air over the valley slopes is unimportant. In fact, it contributes significantly by raising the mean temperature of the air overlying the glacier. Generally, the heated air moves upward in the slope winds perpendicular to the valley axis and descends over the middle of the glacier. It is therefore not surprising that, in a cross-section, the lowest air temperatures are found at the sides of the glacier. A more extensive study on the role of this cross-valley circulation will be described in a later paper.

\section{ACKNOWLEDGEMENTS}

Members of the field party in the summer of 1989 were W. Boot, L. Conrads, J. Oerlemans, M. Portanger, H. Snellen and $\mathrm{R}$. van de Wal. The co-operation with our colleagues from the University of Innsbruck was very pleasant, and some of their stakes were at the right position to suit our ablation experiment! We also thank E. Uytdehaage for assistance with the ablation and albedo readings on 16 September.

Financial support for this investigation was provided by The Netherlands Organization for Scientific Research (NWO).

\section{REFERENGES}

Dirmhirn, I. and E. Trojer. 1955. Albedountersuchungen auf dem Hintereisferner. Arch. Meteorol. Geophys. Bioklimatol., Ser. B, 6(4), 400-416.

Greuell, W. and J. Oerlemans. 1989. Energy balance calculations on and near Hintereisferner (Austria) and an estimate of the effect of the greenhouse warming on ablation. In Oerlemans, J., ed. Glacier fluctuations and climatic change. Dordrecht, Kluwer Academic Publishers, 305-323.

Kerr, J. P., G. W. Thurtell and C. B. Tanner. 1967. An integrating pyranometer for climatological observer stations and mesoscale networks. F. Appl. Meteorol., 6, 688-694.

Kuhn, M. 1979. On the computation of heat transfer coefficients from energy-balance gradients on a glacier. J. Glaciol., 22(87), 263-271.

Kuhn, M. 1981. Begleitworte zur Karte des Hintereisferners 1979, 1:10.000. Z. Gletscherkd. Glazialgeol., 16(1), 1980, 117-124. [Map in pocket.]

Mannstein, H. 1985. The interpretation of albedo measurements on a snow covered slope. Arch. Meteorol. Geophys. Bioklimatol., Ser. B, 36, 73-81.

Oerlemans, J. and N.C. Hoogendoorn. 1989. Massbalance gradients and climatic change. 7. Glaciol., 35(121), 399-405.

Wendler, G. 1975. A note on the advection of warm air towards a glacier. A contribution to the International Hydrological Decade. Z. Gletscherkd. Glazialgeol., 10, 1974, 199-205.

The accuracy of references in the text and in this list is the responsibility of the authors, to whom queries should be addressed.

\section{APPENDIX}

The mini-albedometer consists of two parts, the sensor 


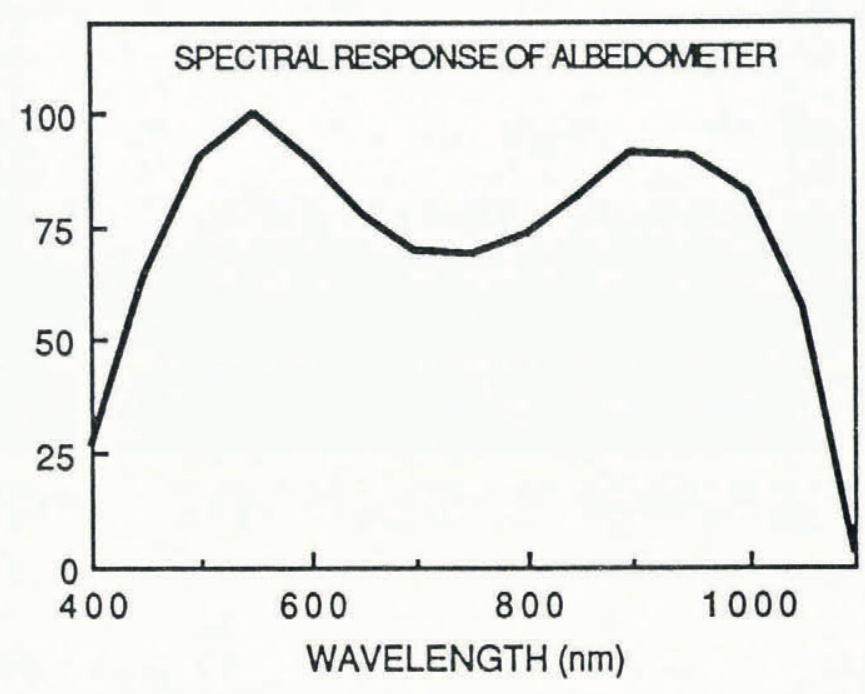

Fig. 7. Spectral response of the albedometer.

and the display. The sensor head is mounted on a $10 \mathrm{~mm}$ fiberglass rod of $1 \mathrm{~m}$ length. The handle of the rod carries a small spirit level, aligned with the sensor axis in order to be able to hold the albedometer in a horizontal position. A thin flexible cable emerging from the handle can be plugged into a pocket-size box containing an analog current divider to process the signals, displaying the albedo on an LCD in three digits. The complete instrument, including two $9 \mathrm{~V}$ batteries, weighs $460 \mathrm{~g}$.

The sensor head accommodates two silicon diodes BPW34, both with a blue-enhancement filter, covered by white Perspex diffusers to ensure a good cosine response. The diffuser was made after a design by Kerr and others (1967), who claimed a cosine response of $100 \pm 5 \%$ between $0^{\circ}$ and $85^{\circ}$. We can confirm these specifications in a laboratory test. The diffuser has no significant absorbance in the spectral range between 400 and $1200 \mathrm{~nm}$. The filter is cut from B + W 080 blue glass, manufactured by Schneider in Kreuznach. The spectral response of the complete sensor (diode, blue filter and diffuser) is shown in Figure 7.

The mini-albedometer is designed for field measurements of the surface-energy balance. The contribution of the short-wave radiation to the energy balance is relatively small in the morning and in the evening. Therefore, it can be tolerated that the albedometer ceased to function properly when the global short-wave radiation is below $60 \mathrm{Wm}^{-2}$. An immediate check on the correct performance of the instrument can be made any time in the field by inverting the sensor. This should result in a read-out value which is the inverse of the original
Table 2. Comparison of the mini-albedometer with a thermopile instrument

\begin{tabular}{lccl} 
Surface & SRI 5 & Mini & Sky \\
\hline White sand & 0.32 & 0.33 & clear \\
Yellow sand & 0.38 & 0.38 & clear \\
Yellow sand & 0.29 & 0.30 & overcast
\end{tabular}

value obtained with the sensor in an upright position.

The mini-albedometer has been compared to a conventional thermopile albedometer, type SRI 5, above sand, to check the absolute values of the instrument. The results are presented in Table 2 .

A comparison of the readings from the minialbedometer with the daily mean albedo values measured by the Aanderaa sensors (type 2770) at the location C3 (see Fig. 1) is shown in Figure 8. The distance between the mast on which the Aanderaa sensors were mounted to the stake where the mini-albedometer was read is about $10 \mathrm{~m}$. In view of this, the agreement is good. The minialbedometer was also held at the very same location as the Aanderaa sensors on the mast. The differences appeared to be very small: always less than 0.02 for both cloudy and clear conditions. Altogether, these comparisons gave sufficient confidence in the applicability of the minialbedometer to map the albedo on the glacier tongue.

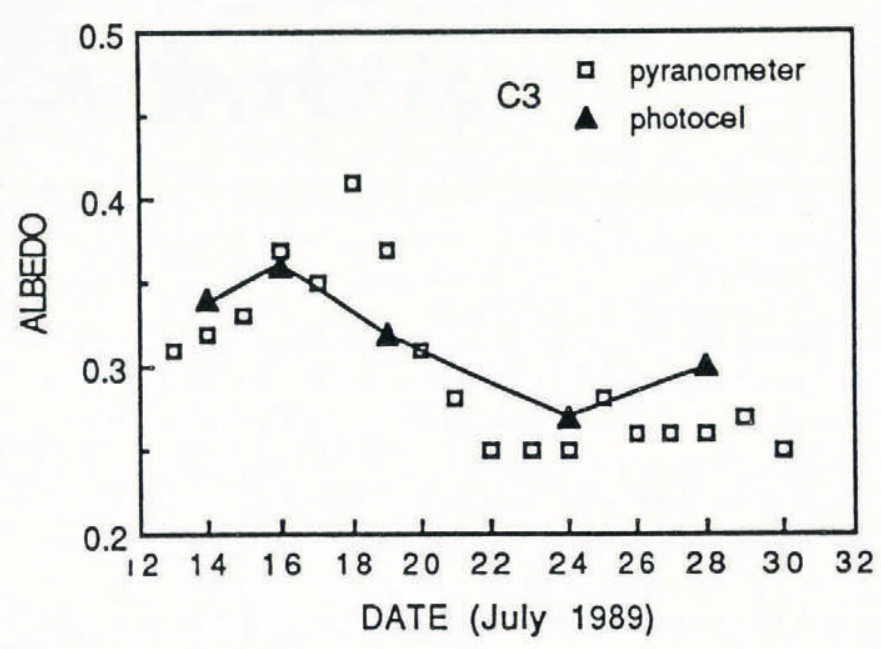

Fig. 8. A comparison of the mini-albedometer with the radiation measurements obtained from the mast at C3. 